\title{
RAUL DA FERRUGEM AZUL: DISCUTINDO O PAPEL DO ESPECTADOR DE BULLYING A PARTIR DA LITERATURA ${ }^{1}$
}

\author{
RAUL DA FERRUGEM AZUL: DISCUSSING THE ROLE OF BULLYING'S SPECTATOR \\ BASED ON LITERATURE
}

\section{RAÚL PINTADO DE AZUL: DISCUTIENDO EL PAPEL DEL ESPECTADOR DEL INTIMIDACIÓN A PARTIR DE LA LITERATURA}

\author{
Lívia Cristina Cortez Lula de Medeiros²
}

\begin{abstract}
Resumo: $\mathrm{O}$ artigo é recorte de uma tese de doutorado vinculada à Universidade Federal do Rio Grande do Norte (UFRN). Seu objetivo é apresentar como a leitura de literatura pode ser trabalhada para se discutir o papel dos espectadores em situações de bullying entre escolares, levando-os a refletirem sobre a violência entre pares. Nesse estudo, o foco da discussão recai sobre o conto "Raul da Ferrugem Azul", de Ana Maria Machado (2012). Metodologicamente, caracteriza-se como uma pesquisa com intervenção. O locus de sua realização foi uma escola pública do Município de Natal - RN (BRASIL), em uma turma de $5^{\circ}$ ano do Ensino Fundamental. Na intervenção pedagógica, realizaram-se dois encontros para a leitura e discussão do conto de Machado (2012). As sessões foram estruturadas a partir da andaimagem (GRAVES; GRAVES, 1995), levando-se em consideração os momentos de pré-leitura, leitura e pós-leitura. Sua análise ancorou-se em princípios da Análise de Conteúdos (BARDIN, 2010), sendo abordadas as seguintes categorias: motivação à leitura, estímulo à discussão, incentivo à reflexão, relação texto-vida e da reflexão ao julgamento. Os resultados da análise revelam que a mediação pedagógica, construída com base em questionamentos, foi de suma importância para que os sujeitos pudessem agir ativamente nas sessões de leitura e construíssem relações entre a violência na ficção e o modo de agir dos espectadores na vida real, considerando as agressões presentes cotidianamente no ambiente escolar. Palavras-chave: Literatura; bullying; espectadores.
\end{abstract}

\begin{abstract}
The article is part of a doctoral thesis linked to the Rio Grande do Norte Federal University (UFRN). Its objective is to present how the reading of literature can be used to discuss the role of spectators in situations of bullying among students, leading them to reflect on violence between peers. In this study, the focus of the discussion is on the story "Raul da Ferrugem Azul", by Ana Maria Machado (2012). Methodologically, it is characterized as a research with intervention. The locus was a public school in the Natal - RN (BRASIL), in a 5th grade class of elementary school. In the pedagogical intervention, two meetings were held to read and discuss the Machado's story (2012). The sessions were structured from the scaffolding (GRAVES; GRAVES, 1995), taking into account the moments of pre-reading, reading and post-reading. Its analysis was based on the principles of Content Analysis (BARDIN, 2010), addressing the following categories: motivation to read, encouragement to discussion, encouragement to reflection, text-life relationship and from reflection to judgment. The results of the analysis reveal that pedagogical mediation, built on the basis of questions, was important for students to act actively in reading sessions and build

\footnotetext{
${ }^{1}$ Este artigo é oriundo de tese de doutorado (Do mundo da literatura à formação do leitor: a contribuição da leitura de contos para se discutir o bullying na sala de aula, 2020) defendida no Programa de Pós-Graduação em Educação da Universidade Federal do Rio Grande do Norte.

${ }^{2}$ Instituto Federal de Educação, Ciência e Tecnologia da Paraíba (IFPB).
} 
relationships between violence in fiction and the way of acting of spectators in real life, considering the aggressions present daily in the school environment.

Keywords: Literature; bullying; spectators.

Resumen: Este artículo científico es parte de una tesis doctoral vinculada a la Universidad Federal del Rio Grande do Norte (UFRN). Su objetivo es presentar cómo la lectura de la literatura puede ser usada para discutir el papel de los espectadores en situaciones de intimidación entre los estudiantes, llevándolos a reflexionar sobre la violencia entre pares. En este estudio, el foco de la discusión está en el cuento "Raúl pintado de azul", de Ana Maria Machado (2012). Metodológicamente, se caracteriza por ser una investigación con intervención. El lugar de su realización fue una escuela pública en la ciudad de Natal-RN (BRASIL), en una clase de quinto grado. En la intervención pedagógica, se realizaron dos encuentros para leer y discutir el cuento de Machado (2012). Las sesiones se estructuraron desde el andaimaje (GRAVES; GRAVES, 1995), teniendo en cuenta los momentos de prelectura, lectura y poslectura. Su análisis se basó en los principios del Análisis de Contenido (BARDIN, 2010), abordando las siguientes categorías: motivación para leer, estímulo a la discusión, estímulo a la reflexión, relación texto-vida y de la reflexión al juicio. Los resultados del análisis revelan que la mediación pedagógica, construida a partir de preguntas, fue de suma importancia para que los sujetos pudieran actuar activamente en las sesiones de lectura y construir relaciones entre la violencia en la ficción y la forma de actuar de los espectadores en la vida real, considerando las agresiones presentes a diario en el entorno escolar.

Palabras clave: Literatura; intimidación; espectadores.

\section{Introdução}

[...] Escolas que são asas [...] amam [...] os pássaros em vôo. Existem para dar aos pássaros coragem para voar $[\ldots]$

Rubem Alves, 2001

A ideia de escola como espaço de liberdade e de ensino para alcançar essa liberdade, tal como concebida por Alves (2001), vai de encontro à violência constantemente presenciada no contexto escolar, como é o caso do bullying (OLWEUS, 2006). E, lamentavelmente, em se concretizando a perspectiva de ocorrência dessa prática, suprimem-se liberdades individuais. Afinal, não se pode negar o fato de que onde há violência se poda a liberdade, especialmente a daqueles que são vitimizados e se sentem intimidados de forma recorrente.

Assimilada essa ideia e acreditando no quanto a escola pode ser um espaço acolhedor para que os estudantes tenham a possibilidade de alçar voo, vislumbramos a literatura como um caminho possível para esse alcance, uma vez que esta proporciona a cada leitor (em cada leitura) uma experiência particular, capaz de levá-lo a outros tempos e mundos inimagináveis fora do texto literário. Essa possibilidade é mágica e libertadora; bem à semelhança daquela sensação que experimentam os pássaros quando impulsionados por suas asas, que, na visão simbólica de Alves (2001), deveriam servir aos seres humanos cumprindo essa mesma finalidade.

Se olharmos com mais acuidade para os textos literários, constataremos que, para além do prazer que despertam no leitor, eles são capazes de ensinar sobre a vida e sobre as relações humanas comuns e corriqueiras, permitindo a reflexão sobre inúmeras questões que afligem o nosso dia a dia. Tendo em mira essa dupla face da literatura - prazer e ensinamento propusemo-nos este trabalho, pensando na essencialidade de sua presença na sala de aula. 
Diante dessa compreensão e entendendo que a prática de bullying é um mal presente nas escolas que necessita ser discutido (OLWEUS, 2006), é que buscamos desvelar a interface literatura e bullying, compreendendo essa prática à luz do conceito elaborado por Olweus (2006, p. 9, tradução nossa),"[...] Bullying ou 'vitimização', de um modo geral, se caracteriza quando uma pessoa é atacada ou "vitimizada" e exposta, repetidamente, a ações negativas partidas de uma ou mais pessoas" 3 , configurando-se como agressão física, verbal ou psicológica intencional, repetitiva e sistemática entre pares, sem motivação aparente, em que há desequilíbrio de poder entre agressor e vítima. Para além disso, também pode desencadear problemas psicológicos, físicos e sociais, em decorrência do sofrimento constante vivenciado pela vítima (OLWEUS, 2006).

Para esse estudo, considerando esse conceito e a referida interface, delimitamos o nosso foco sobre o papel do espectador no cenário de violência, isto é, aquela pessoa que presencia a agressão e que pode assumir dois posicionamentos: passivo - que não concorda com os atos de bullying, porém não toma qualquer ação, ou ativo - que reforça a agressão.

Partindo dessa delimitação, temos como objetivo apresentar como a leitura de literatura pode ser trabalhada para se discutir o papel dos espectadores em situações de bullying entre escolares, levando-os a refletirem sobre a violência entre pares. Para alcançarmos esse objetivo, trazemos à baila a discussão do conto "Raul da ferrugem azul" de Ana Maria Machado (2012), que conta a história de um garoto chamado Raul que, ao se manter inerte diante da violência que presencia, observa o surgimento gradativo de manchas azuladas pelo seu corpo.

Metodologicamente essa discussão foi desenvolvida a partir de uma pesquisa qualitativa com intervenção realizada em uma turma do $5^{\circ}$ ano do Ensino Fundamental I, em que participaram 20 sujeitos (12 meninas e 8 meninos), numa faixa etária entre 10 e 12 anos. Para a leitura do conto de Machado (2012) foram realizadas duas sessões de leitura estruturadas a partir da andaimagem (scaffolding), método apresentado por Graves e Graves (1995), em que a mediação deve partir das inferências desenvolvidas pelos aprendizes para então chegar a um novo conhecimento. Nesse processo, o planejamento das ações do mediador é fundamental, e deve levar em conta o públicoalvo e a adequação quanto à escolha do texto, com foco principal nas suas potencialidades.

Segundo esses autores, a instituição da leitura deve compreender três momentos: a préleitura, que tem por objetivo motivar os sujeitos, criar expectativas sobre o texto, ativar os conhecimentos prévios e fazer uma pré-abordagem do vocabulário existente; a leitura, que oportuniza a aproximação/a exploração do texto de várias maneiras (a leitura silenciosa, a leitura guiada, a leitura oral realizada pelo docente ou pelos estudantes); e a pós-leitura, que dá condições aos aprendizes de organizarem o que compreenderam do texto, a partir da reflexão, do questionamento e da discussão. Esse momento, em particular, fornece indícios importantes para que o mediador possa avaliar a sua intervenção e desenvolver atividades criativas que estimulem o aprendiz a pensar sobre o texto e a estabelecer relações com sua realidade.

Partindo dessa introdução, apresentaremos a análise das sessões de leitura ancorada em princípios da Análise de Conteúdos (BARDIN, 2010), em que foram construídas categorias relativas às unidades de registro "Mediação Pedagógica" e "Relação texto literário x bullying". Após o desenvolvimento da análise, delinearemos algumas considerações finais.

\section{O espectador no conto Raul da ferrugem azul: da leitura à reflexão}

[...] Um ponto antes de saltar, viu que a lavadeira tinha tocado a campainha para descer. E bem na hora em que ela ia descendo os degraus, carregando

\footnotetext{
${ }^{3}$ Bullying or victimization in the following general way: A students is being bullied or victimized when he or she is exposed, repeatedly and over time, to negative actions on the part of one or more other students.
} 
aquela trouxa pesada, o motorista acelerou o motor, fazendo um barulhão e reclamando porque ela estava demorando: [...]

Raul ficou uma fera. E começou a falar: - Moço, o senhor não está vendo que ela está descendo e carregando peso? Faça o favor de esperar.

O motorista respondeu: - A conversa não chegou na cozinha. Cala a boca, pirralho. Sem pensar, Raul respondeu:

- Cala a boca já morreu. Quem manda em mim sou $e u$.

Enquanto esperava o elevador, se olhou no espelho. [...] E teve uma surpresa: a ferrugem do pescoço tinha desaparecido. Abriu a boca, botou a língua para fora. Nem sinal de ferrugem na garganta. Olhou depressa para os braços e as pernas. Lá ainda havia as manchas azuis. Mas bem mais fracas. E agora ele não se preocupava mais com elas. Sabia que iam sumir. Raul da ferrugem azul, p. 57-59

Raul, um belo dia, percebe que está com uma mancha azul no braço e, por mais que pense sobre a questão, não consegue achar resposta plausível para tal ocorrência. Ele faz diversas tentativas para remover as manchas: toma banho de sol, esfrega-as bastante, busca até mesmo mostrá-las aos pais na esperança de ser ajudado. Contudo, percebe que apenas ele enxerga as manchas e que, sozinho, precisará achar a solução para o problema.

É com a ajuda da pequena Estela que Raul dá importantes passos para se libertar, não apenas das incômodas manchas, mas, principalmente, da falta de iniciativa diante das injustiças que observa ao seu redor. Ele se tornou capaz de agir de acordo com as suas convicções: "Cala a boca já morreu. Quem manda em mim sou eu"!

As ações da personagem principal assemelham-se ao papel desempenhado pelo tipo espectador passivo que atribui a culpa a si mesmo pelas situações que contemplam (AVILÉS et al., 2011), contudo, permanecem inertes frente às cenas de bullying, dando margem também para a reflexão sobre o espectador ativo, aquele que, direta ou indiretamente, reforça a agressão.

Para essa análise destacamos 4 episódios, que exemplificam as seguintes categorias: "motivação à leitura", "estímulo à discussão" e "incentivo à reflexão" (Unidade: Mediação Pedagógica) "relação texto-vida" e "da reflexão ao julgamento" (Unidade: Relação texto literário x bullying).

Conforme mencionamos, a leitura do conto Raul da ferrugem azul (MACHADO, 2012) foi realizada em duas sessões. Por essa razão, as expectativas levantadas pelos sujeitos puderam embasar-se em momentos distintos do texto.

Na primeira sessão, realizamos a motivação à leitura a partir da imagem presente na capa e do título do conto (turno 7). 
(7) PP: [...]. Olhem para a imagem e o título do livro [...]. Pensando aqui no título e na imagem sobre o que vocês acham que vai falar a história?

(8) Priscila: Ele olhando num espelho azul?

$[\ldots]$

(21) PP: [...]. Mas e Raul [...] Que relação tem Raul e a ferrugem azul? Que relação vocês conseguem fazer?

(22) Yasmin: O espelho azul que enferrujou.

(23) PP: E Raul onde entra nessa história?

(24) Ângelo: Uma parte dele é robô e outra é menino.

(25) PP: E a parte do robô enferrujou? ((Ângelo diz que sim)) Será? Alguém mais tem alguma ideia?

$[\ldots]$

(42) Ester: Será que ele não tem um negócio assim, sei lá, que enferruja?

$[\ldots]$

(83) Ângelo: Então eu acho que ele caiu e ficou machucado no braço.

$[\ldots]$

(85) Lívia: Professora, pode ser que a parte que era de ferro, $((+))$ pode ser que ele tinha caído, aí tava enferrujada e ele se cortasse.

(86) Ângelo: Ou, então, a parte de ferro dele ((+)) ele caiu e enferrujou.

(87) PP: Ele caiu, se esfolou e enferrujou? Vamos ver agora [...]

(88) Ângelo: Ou, então, professora, ele se guardou por tanto tempo, que ficou criando ferrugem.

(89) PP: Será? Vamos ver na história se foi isso?

Quadro 1: Episódio 1 - Fonte: Elaboração própria

Inicialmente, Priscila foi a única a responder a questão (turno 7), demonstrando alguma incerteza quanto ao que estava falando, vez que a sua resposta foi interrogativa (turno 8). Em razão de sua vaga resposta em relação aos elementos apresentados - título e imagem - e ao silêncio dos demais sujeitos, procuramos esclarecer melhor o que desejávamos que os alunos pensassem (turno 21), reforçando a questão em seguida (turno 23) e buscando expandir o diálogo (turno 25). Percebemos que essa nossa insistência no sentido de reformular os questionamentos e em mediar as respostas favoreceu a assunção de posicionamentos por parte dos sujeitos, que passaram a expressar as suas previsões (turnos 24 e 42).

De acordo com Bortoni-Ricardo, Machado e Castanheira (2010, p. 27-28), a

sobreposição da fala do professor à do aprendiz, auxiliando-o na elaboração de seu enunciado, de sinais de retorno, comentários, reformulações, reelaboração e paráfrase e, principalmente, expansão do turno da fala do aluno [...] dão a ele a oportunidade de 'reconceptualizar' seu pensamento original, seja na dimensão cognitiva, seja na dimensão formal.

Essa reelaboração e expansão do turno podem ser observadas nas respostas de Lívia (turno 85) e de Ângelo (turnos 86 e 88), que voltaram às previsões mesmo após o pré-ensino do vocabulário - segunda etapa planejada na pré-leitura. Isso nos mostra que a dinamicidade e a não linearidade do trabalho desenvolvido na sala de aula apresenta um constante processo de adiantar e retroceder, cabendo ao professor "facilitar os processos de elaboração da criança e acompanhar o curso do seu desenvolvimento, ouvindo suas elaborações e situando-as em 
termos das possibilidades lógicas da representação" (FONTANA, 2000, p. 163), conforme buscamos realizar (turnos 87 e 89 ).

Almejando a ampliação dos discursos no que concerne ao conto, estimulamos os sujeitos a discutirem e justificarem suas respostas, como podemos observar no episódio a seguir.

(95) PP: [...] e aí, ele enferrujou?

(96) ASRJ: Sim. ((parte dos alunos)).

(97) ASRJ: Não. ((outra parte dos alunos)).

(98) PP: Sim ou não? Por que que você acha que sim? ((apontando para Ângelo)) E por que você acha que não? ((apontando para Priscila)).

(99) Ester: Porque ele tava ficando azul.

(100) Priscila: Professora, sabe por que eu acho que não, porque quando ele olhava no espelho, o espelho tava azul, aí ele pensava que tava com a pele azul e por isso que ninguém via e ele não tava nada de azul.

(101) Ester: Não, que quando ele olhava pro braço ((a aluna olha para o braço)), ele via azul. (117) Priscila: Mas como é que ele ficou com a pele azul e ninguém viu?

\section{$[\ldots]$}

(124) PP: Por que será que ninguém vê?

\section{$[\ldots]$}

(126) Lívia: Professora, eu acho que é porque é $((+))$ ele tá, tá ficando tipo velho e não conseguia andar direito, que naquela hora do $((+))$ do balão.

(127) PP: Ele ficou parado e não conseguiu reagir, é verdade, ele não conseguiu agir, por quê?

(128) Ângelo: É como se ele tivesse enferrujado e ficou parado. Não conseguiu (...).

(129) Lívia: Não tava conseguindo se mover.

$[\ldots]$

(143) Lívia: Professora, eu já sei, eu acho que isso é raiva, porque toda vez que aparece manchinha nele é porque ele ficou com raiva.

(144) Priscila: Raiva de bater no povo. De espancar o povo.

(145) PP: Raiva de espancar ou de não espancar?

$[\ldots]$

(147) Lívia: De querer espancar e não poder.

(148) PP: Então, ele quer revidar, mas não revida e as manchas aparecem, é assim?

(149) ((Lívia concorda)).

$[\ldots]$

(152) SNI: Foi a raiva dele.

(153) PP: A raiva dele, que fez ele enferrujar? E por que vocês acham que acontecia isso? Quando ele tinha uma raiva, ele enferrujava?

(154) Priscila: Porque ele não podia bater.

Quadro 2: Episódio 2 - Fonte: Elaboração própria

Esse diálogo realizou-se na pós-leitura da primeira sessão de leitura do conto, ou seja, os sujeitos já tinham algum repertório sobre o enredo da história para discutir e fazer suas inferências com relação à situação vivida por Raul.

Iniciamos a pós-leitura retomando o conflito gerado na pré-leitura sobre o fato de a personagem ter enferrujado ou não. Nota-se que os sujeitos ainda não chegaram a um consenso quanto à questão (turnos 96 e 97). 
Levando em consideração as opiniões contrárias, questionamos, mais uma vez, os sujeitos com o objetivo de que justificassem seus posicionamentos (turno 98). Para Ester, estava claro o fato de Raul enferrujar, em virtude da cor azul que foi aparecendo nele ao longo da história (turno 99). Priscila, por sua vez, discordou e afirmou que o espelho é que era azul, e que tudo não passava de imaginação do garoto. Ela argumentou que era inconcebível Raul estar com manchas azuis e ninguém conseguir enxergar isso (turno 100).

É interessante observar a construção da argumentação neste episódio. Ante à colocação de Priscila, Ester contra-argumentou, afirmando que não podia ser o espelho, uma vez que a personagem olhou diretamente para o braço e o viu com manchas azuis (turno 101). Para formular essa afirmação e embasar sua contra-argumentação, Ester utilizou-se do próprio texto, mostrando, portanto, a validade de seu argumento (PERELMAN; TYTECA, 2005), de modo a substanciar o seu discurso. Como bem justifica Koch,

[...] a argumentação é uma atividade estruturante do discurso, pois é ela que marca as possibilidades de sua construção e lhe assegura a continuidade. É ela a responsável pelos encadeamentos discursivos, articulando entre si enunciados ou parágrafos, de modo a transformá-los em texto: a progressão do discurso se faz, exatamente, através das articulações da argumentação (KOCH, 2000, p. 159).

Buscando, portanto, a desejada progressão do discurso, e também nos aproveitando da afirmação de Priscila (turno 117), que ainda não estava convencida de que Raul enferrujava, estimulamos o aprofundamento da questão em torno dessa temática (turno 124). A partir desse questionamento, os sujeitos começaram a fazer inferências com base nos indícios oferecidos pelo texto até aquele momento.

Lívia (turno 126) argumentou que o personagem estava "tipo ficando velho" e que, por essa razão, não conseguiu andar direito. Na verdade, ela construiu uma relação entre a atitude de Raul e a sua experiência de mundo: com o avançar da idade, as pessoas passam a ter limitações para se locomover.

Apoiando-nos na resposta de Lívia, elaboramos outra questão (turno 127) com o objetivo de que os sujeitos refletissem sobre suas respostas e pudessem justificá-las de forma mais convincente. Ângelo iniciou sua argumentação sobre o porquê de Raul não ter conseguido reagir, relacionando o fato de a personagem ter perdido a mobilidade em virtude da ferrugem, ou seja, também elaborou sua resposta a partir do que conhece sobre ferrugem: o fato de Raul estar enferrujado tornava-o enrijecido; portanto, menos capaz de locomover-se (turno 128). Seguindo esse mesmo raciocínio, Lívia complementou a fala do colega, concluindo o seu pensamento: "Não tava conseguindo se mover" (turno 129).

Observa-se que tais respostas não estavam explicitadas no texto, o que exigiu que os sujeitos fizessem inferências. Esse processo requer que o leitor olhe para além do que está posto pelo autor, levando-o a um outro patamar de entendimento, que foge ao literal. A colocação de Lívia (turno 143) exemplifica o modo como os indícios apresentados pelo texto podem ser utilizados pelo leitor para chegar a uma conclusão categórica: "Professora, eu já sei, eu acho que isso é raiva, porque toda vez que aparece manchinha nele é porque ele ficou com raiva". Essa afirmação foi construída pela discente a partir de sua reflexão sobre as ações da personagem diante de situações de violência.

Priscila, por sua vez, apoiando-se na fala de Lívia, relacionou a raiva ao ato de agredir (turno 144). Questionamos, então, a colocação de Priscila (turno 145), que foi prontamente explicada por Lívia, numa tentativa de justificar o sentimento da personagem diante das agressões: querer revidar, mas nada fazer (turno 147). 
Como forma de ratificar o pensamento desenvolvido até aquele momento, buscamos confirmar o que estava sendo posto na discussão (turno 148). Isso levou Priscila a reavaliar seu posicionamento anterior, de tal modo que ela passou a afirmar o contrário do que havia dito. A nosso ver, é uma prova de que a argumentação convincente construída por Lívia (turnos 143 e 147), a partir das questões mediadas, obteve a adesão (PERELMAN; TYTECA, 2005) de Priscila, que reestruturou o seu discurso, numa demonstração de mudança de comportamento (turno 154).

Na segunda sessão, buscamos incentivá-los a refletir sobre a condição da personagem principal, ao mesmo tempo em que buscávamos fazer com que eles desenvolvessem a relação texto-vida, elaboramos o seguinte questionamento (turno 426), que serviu para desencadear uma reflexão bem fecunda.

(426) PP: Vocês acham que vocês já enferrujaram alguma vez em alguma situação, como aconteceu com Raul?

(427) Priscila: Não.

$[\ldots]$

(430) PP: Vocês sempre ajudam o colega que está sofrendo alguma violência? Ou já aconteceu de vocês ficarem paralisados como Raul?

(431) Carla: Não, tipo assim: se for amigo meu, eu ajudo.

(432) SNI: Muita gente não ajuda, não.

(433) Ítalo Gabriel: Eu não ajudo não, ajudo batendo (...)

(434) Priscila: Se não for conhecido, eu deixo se virar, vou me intrometer nas coisa que eu não sou chamada.

(435) PP: Mesmo se for aqui, na escola, algum colega de uma outra turma que você não conheça?

(436) Priscila: Se for aqui, na escola, até ajudo, chamando a diretora e pronto.

Quadro 3: Episódio 3 - Fonte: Elaboração própria

Como visto, focando, inicialmente, na inércia da personagem Raul, diante das agressões observadas, elaboramos uma questão com o propósito de levar os sujeitos a refletirem sobre suas próprias reações, caso estivessem no lugar de Raul (turno 426). Um sujeito (SNI - sujeito não identificado), tomando a resposta de Carla (turno 431), fez uma ressalva afirmando que "muitos não ajudariam" (turno 432). Prosseguindo com a discussão e, ratificando o dito pelo colega, Ítalo Gabriel não apenas afirmou que não auxiliaria, mas ainda deixou claro que ajudaria a agredir (turno 433). Após essa colocação de Ítalo, Priscila reformulou o seu posicionamento, fazendo a ressalva de que também ajudaria uma pessoa que fosse conhecida, caso contrário, "deixaria se virar", porque não se meteria onde não fosse chamada (turno 434).

Compreendendo que o espectador é um agente importante - até mesmo decisivo - e que faz a diferença quando intervém em uma situação de conflito (ROWE, 2018), elaboramos um novo questionamento, almejando focar na figura do espectador e na sua atuação dentro da escola (turno 435).

Priscila afirmou que "até" ajudaria se fosse um colega desconhecido da escola, ressaltando, porém, que seria um tipo de ajuda indireta: chamar a diretora (turno 436), por exemplo. Acreditamos que se, de fato, os espectadores dos conflitos existentes naquela escola agissem em prol da vítima, ainda que fosse simplesmente comunicando a algum integrante da gestão escolar a ocorrência do ato de violência, já seria uma vitória, considerando-se os inúmeros conflitos constatados naquele ambiente escolar. 
Essa relação texto-vida também pôde ser observada em outro momento, considerado, por nós, um dos mais frutíferos para a reestruturação do pensamento dos sujeitos, em virtude das diferentes opiniões que nele emergiram, o que nos possibilitou observar aspectos de reflexão e julgamento.

$[\ldots]$

(187) PP: Pensando aqui na escola: se no intervalo estão pegando algum objeto de um colega e vocês vão (...)

(188) Ester: Eu já tomei algum brinquedinho de André ((colega de turma que possui o espectro autista)) que a menina tava pegando.

(189) PP: Para ajudá-lo? ((Ester afirma que sim)). Então você o defendeu.

(190) Ítalo Gabriel: Eu deixava, professora.

(191) PP: Você deixaria? E por que você não ajudaria?

(192) Priscila: Porque ele é ruim.

(193) PP: Deixem Ítalo Gabriel responder.

(194) Ítalo Gabriel: Porque eu não quero.

(195) PP: Então você preferiria ser um espectador, só assistir o que estavam fazendo com o seu colega, sem ajudar. Será que existe a possibilidade de, às vezes, a gente não ajudar com medo que venham brincar com a gente, mexer com a gente também?

(196) Ítalo Gabriel: Aí ia pro pau.

(197) Priscila: Se mexer comigo, eu dou um bofete. Eu vou deixar (...)

(198) PP: Mas, vocês acham que isso pode acontecer, de eu não ajudar o outro porque eu tô com vergonha, como Lívia falou, ou eu tô com medo que o outro venha mexer comigo? (199) ASRJ: Pode.

(200) Ítalo Gabriel: Só se eu quiser, professora. ((supõe-se que o aluno está se referindo à questão sobre ajudar ou não um colega que está em apuros)).

(201) Ângelo: Nada a ver, professora. Eu ajudava porque se o outro que tava mexendo com meu amigo viesse pra cima de mim, meu amigo ia me proteger do mesmo jeito que eu protegi ele.

(202) Ester: Ângelo, podia ser o contrário, o outro vir para cima de você e seu amigo ficar "briga, briga".

(203) Ítalo Gabriel: Aí você ficava apanhando lá e o outro nem (...).

Quadro 4: Episódio 4 - Fonte: Elaboração própria

Ao contrário de Ester, que registrou o fato de ter ajudado André quando mexeram com ele (turnos 188 e 189), Ítalo foi enfático ao afirmar que não se meteria, ou seja, deixaria o colega ser perturbado (turno 190).

Esse modo de encarar a violência quando destinada a terceiros, tal qual fez Ítalo, foi constatado em pesquisas reportadas por O’Connell, Pepler, Craig (1999, p. 438, tradução nossa):

Craig e Pepler (1997) examinaram observações de parques infantis e descobriram que os pares estavam envolvidos, de alguma forma, em $85 \%$ dos episódios de bullying. [Entretanto], [a] [...] intervenção desses pares ocorreu [apenas] em 11\% dos episódios. Esta relativa falta de intervenção [...] provavelmente reforça os intimidadores, que podem interpretar que seus colegas são tolerantes ao bullying ${ }^{4}$.

\footnotetext{
${ }^{4}$ Craig and Pepler (1997) examined coded playground observations and found that peers were involved, in some capacity, in $85 \%$ of bullying episodes. [However], [the] peers intervened [only] in $11 \%$ of bullying episodes. This relative lack of intervention [...] is likely to reinforce bullies, who may interpret peers' behaviors as condoning bullying.
} 
Percebe-se, pela análise dos dados apresentados, que há um alto índice de espectadores que preferem não intervir considerando "o [...] poder que os agressores desfrutam, aliado às preocupações de autopreservação [...]. [Isso porque] quando [...] intervêm, correm o risco de tornarem-se as próximas vítimas"5 (O’CONNELL; PEPLER; CRAIG, 1999, p. 439, tradução nossa). Essa razão, porém, apesar de ter sido levantada (turno 195), não condizia com o pensamento de Ítalo Gabriel (turno 196), que, mais uma vez, não demonstrando (ou não desejando demonstrar) qualquer tipo de vulnerabilidade, respondeu recorrendo ao uso da violência (turno 196), tendo o seu posicionamento sido seguido por Priscila (turno 197).

Com o propósito de ampliar a discussão, fizemos uma indagação que conduzisse os sujeitos a pensarem em relações de natureza "macro" e não somente nas suas relações com os colegas na escola (turno 198), o que levou alguns deles a responderem afirmativamente (turno 199).

Ítalo Gabriel, mais uma vez, entrou em cena, relativizando a sua afirmação anterior sobre não ajudar o alvo (turno 200), sem responder, entretanto, à última pergunta que havia sido formulada. Ângelo foi quem se ateve à questão proposta e se posicionou contrário a Ítalo, destacando o sentimento de solidariedade e também de camaradagem, em que os amigos se ajudam mutuamente (turno 201). Ester, porém, apresentou um contraponto à afirmação de Ângelo, o que nos conduz a inferir ser aquela uma atitude condizente com a realidade daquela escola (turno 202).

A conduta de proteger o outro, explicitada no contraponto feito por Ângelo, foi desacreditada por Ítalo (turno 203), que deixou claro não crer na solidariedade enfatizada.

De todo modo, mesmo que o impacto da colocação de Ângelo sobre a ajuda mútua não possa ser mensurado no que se refere à reflexão gerada nos demais colegas participantes da discussão, acreditamos que a divergência de pontos de vista favorece tal reflexão. Isto é, pode ter possibilitado a reorganização do pensamento individual dos sujeitos a partir do pensamento exterior - o olhar do outro. Pensamos que esse conto foi importante para que os sujeitos tivessem a oportunidade de enxergar, com mais acuidade, o papel que o espectador (passivo ou ativo) assume quando se trata do bullying.

\section{Considerações finais}

Partindo da discussão construída durante as sessões de leitura da história "Raul da ferrugem azul" (MACHADO, 2012), observamos que o olhar sobre o papel do espectador na prática de bullying pôde ser elaborado pelos sujeitos. Isso foi possível em razão da mediação pedagógica construída a partir de questionamentos que permitiram que os sujeitos passassem a agir ativamente e pudessem expressar seus pontos de vista junto aos seus pares.

Foi apoiando-se nos andaimes, que iam sendo estruturados no momento da discussão, que eles puderam retomar a história, voltar ao texto, e construir relações entre a forma de violência apresentada na ficção e aquela presente no mundo ao seu redor. Isso evidencia que interrelacionar a literatura e o bullying através de um trabalho planejado e com objetivos bem delineados, contribuiu de maneira positiva para a edificação de diálogos fecundos.

Tais diálogos demonstram que houve a identificação dos sujeitos com a personagem principal e as situações ficcionais narradas, o que propiciou o despertar de um olhar mais acolhedor com relação a situação do outro (empatia), na medida em que eles se incomodavam, isto é, se identificavam com a personagem, apontando como agiriam se estivessem em um contexto semelhante. Essa identificação que conduz ao julgamento possibilitou, nesse ínterim, a reflexão sobre o mundo circundante, levando os sujeitos a estabelecerem relações com a

\footnotetext{
${ }^{5}$ The power [...] that bullies enjoy, coupled with peers' concerns for self-preservation [...]. [this because] when $[\ldots]$ intervene they risk becoming the next victims.
} 
realidade. Por fim, a empatia levou-os a julgamentos que chegaram a ultrapassar a própria ficção, atingindo, inclusive, os posicionamentos assumidos pelos colegas, o que revela a potencialidade do texto literário de suscitar a reflexão para além de suas páginas.

\section{Referências}

ALVES, Rubem. Gaiolas e asas. Folha de S. Paulo, Opinião, São Paulo 05 dez. 2001. Disponível em: https://www1.folha.uol.com.br/fsp/opiniao/fz0512200109.htm. Acesso em: 27 jul. 2018.

AVILÉS, José Maria et al. El maltrato entre iguales: "bullying”. Behavioral Psychology/Psicología Conductual, v. 19, n. 1, p. 57-90, abr. 2011.

BARDIN, Laurence. Análise de conteúdo. 5. ed. Lisboa: Edições 70, 2010.

BORTONI-RICARDO, Stella Maris; MACHADO, Veruska Ribeiro; CASTANHEIRA, Salete Flôres. Formação do professor como agente letrador. São Paulo: Contexto, 2010.

FONTANA, Roseli Aparecida Cação. Mediação pedagógica na sala de aula. 4. ed. Campinas: Autores Associados, 2000.

GRAVES, Michael. F.; GRAVES, Bonnie. B. The scaffolding reading experience: a flexible framework for helping students get the most out of text. Reading, p. 29-34, apr. 1995.

KOCH, Ingedore Grunfeld Villaça. Argumentação e linguagem. São Paulo: Cortez, 2000.

MACHADO, Ana Maria. Raul da ferrugem azul. 3. ed. Ilust. R. Faria. São Paulo: Salamandra, 2012.

O'CONNELL, Paul; PEPLER, Debra; CRAIG, Wendy. Peers involvement in bullying: insights and challenges of intervention. Jornal of adolescence, v. 22, p. 437-452, 1999. Disponível em: https://pdfs.semanticscholar.org/e3b0/1033c791c368ddb4b198c083385d46d26645.pdf. Acesso em 24 jun. 2019.

OLWEUS, Dan. Bullying at school: what we know and what we can do. Malden: Blackwell, 2006.

PERELMAN, Chaim; OLBRECHTS-TYTECA, Lucie. Tratado da argumentação: a nova retórica. Trad. M. E. A. P. Galvão. São Paulo: Martins Fontes, 2005.

ROWE, Mary. Fostering constructive action by peers and bystanders in organizations and communities. Negotiation journal, v. 34, n. 2, p. 137-163, apr. 2018.

\section{Sobre a autora}

Lívia Cristina Cortez Lula de Medeiros. Doutora (2020) e Mestre em Educação (2012) pela Universidade Federal do Rio Grande do Norte (UFRN) na linha de pesquisa: Educação, Comunicação, Linguagens e Movimento. Pesquisa, principalmente, os seguintes temas: leitura; teoria literária; literatura; prática educativa; mediação pedagógica; formação do leitor; violência na escola e bullying. Graduada em Pedagogia pela UFRN (2006), tem experiência profissional docente no Ensino Fundamental e na Educação Infantil e como Coordenadora 
Pedagógica em cursos ministrados pela Marinha do Brasil (2010-2014). Especialista em Psicopedagogia pela Universidade Federal do Rio Grande do Norte (2008). Atualmente, é pedagoga do Instituto Federal de Educação, Ciência e Tecnologia da Paraíba (IFPB), integrando a equipe da Coordenação Pedagógica e de Apoio ao Estudante (COPAE).

E-mail: livia.medeiros@ifpb.edu.br. 